\section{Tests of frequency theory in verbal discrimination transfer with varying paradigms and List 1 trials}

\author{
MARK E. KING* and IRWIN P. LEVIN† \\ University of Iowa, Iowa City, Iowa 52240
}

In one verbal discrimination transfer paradigm, the incorrect items from List 1 were used as the incorrect items on List 2 and paired with new correct items. In another paradigm, the correct items from List 1 were used as the incorrect items on List 2 and paired with new correct items. Subjective frequency carryover from List 1 to List 2 was assumed to be greater for the latter paradigm due to the greater frequency buildup of correct items than of incorrect items on List 1 . Frequency effects were also assumed to vary as a direct function of number of List 1 trials. Results were in agreement with these assumptions and with the predictions of frequency theory when S's ability to discriminate recent from remote frequency is taken into account.

Ekstrand, Wallace, \& Underwood (1966) proposed a frequency theory of verbal discrimination (VD) learning which postulates that $S$ bases his discrimination between the two items of a VD pair on differences in the subjective frequency of each unit. The subjective frequency of the correct or right ( $R$ ) item of a pair becomes greater than that of the incorrect or wrong (W) item in a variety of ways: $S$ is told which item is correct following each response and comes to pronounce and rehearse the $R$ item progressively more often than the $W$ item.

Ekstrand et al (1966) applied this theory to the VD transfer effects found in an earlier study by Underwood, Jesse, \& Ekstrand (1964). In the latter study there were three transfer conditions: a control condition containing two unrelated lists, a "right" condition where the $R$ items were the same on both lists with new W items on List 2, and a "wrong" condition in which $W$ items were the same on both lists with new $R$ items on List 2. All Ss learned List 1 items to a criterion of three successive perfect trials. Results showed essentially $100 \%$ transfer for Ss in the "right" condition, suggesting that frequency units from List 1 carried over to List 2 and that Ss responded by choosing the most frequent item in a pair. Transfer performance in the "wrong" condition was more complex. On early trials, Ss in this condition made fewer errors than did control Ss. On later trials, however, Ss in the

*This research was conducted while the first author was a participant in the Undergraduate Research Participation Program of the Department of Psychology at the University of Iowa. This program was supported by National Science Foundation Grant GY-8926.

tRequests for reprints should be sent to Irwin P. Levin, Department of Psychology, University of Iowa, Iowa City, Iowa 52240 . "wrong" condition were unable to improve and eventually performed worse than did control Ss. Ekstrand et al (1966) accounted for the rather unexpected transfer performance in this condition as follows: On early List 2 trials, $S$ can adopt the rule to choose the item with the lowest subjective frequency in each pair. However, the subjective frequency of a new $R$ item increases faster over trials than that of a W item, and at some point the subjective frequencies are approximately equal for $\mathrm{R}$ and $\mathrm{W}$, making discrimination on the basis of frequency more difficult. At this point, $S$ cannot effectively use the rule to choose the least frequent item, and he eventually changes his rule and chooses the most frequent item. The breakdown of discrimination based on frequency and the necessity of a rule change depresses later performance of Ss in the "wrong" condition.

Frequency theory was thus able to account for the transfer effects in the Underwood et al (1964) study. Support for the theory has been found also in other VD transfer studies (e.g. Raskin, Boice, Rubel, \& Clark, 1968). The present study evaluated frequency theory in VD transfer tasks incorporating new manipulations designed to affect frequency carryover from List 1 to List 2.

In addition to the usual control condition with completely new items on Lists 1 and 2, two transfer conditions were included. One of these was analogous to that used by different. A condition like the "wrong" condition of Underwood et al was employed, with the $W$ items being the same for Lists 1 and 2 and the $\mathrm{R}$ items being different. Hereafter, this condition will be referred to as $\mathrm{W} \rightarrow \mathrm{W}$ to indicate that $\mathrm{W}$ items from List 1 were used as $W$ items in List 2. Underwood et al (1964), and one was
In the other transfer condition, $R$ items from List 1 became the $W$ items for List 2 , and there were new $R$ items for List 2. Hereafter, this condition will be referred to as $\mathrm{R} \rightarrow \mathrm{W}$ to indicate that $\mathrm{R}$ items from List 1 were used as $W$ items in List 2. Within Conditions $W \rightarrow W$ and $R \rightarrow W$, there was a manipulation of number of List 1 trials. Ss received 2, 4, or 8 trials on List 1. Those $S$ s receiving the greatest number of List 1 trials should show the greatest carryover of subjective frequency to List 2 .

Predictions from frequency theory are as follows: (1) Each group with $\mathrm{W} \rightarrow \mathrm{W}$ and $\mathrm{R} \rightarrow \mathrm{W}$ conditions should do better than a control group on early List 2 trials but poorer on later trials when discrimination based on frequency breaks down, thus replicating the crossover interaction found by Underwood et al (1964). (2) The crossover effect should vary as a function of number of List 1 trials. Specifically, the amount by which performance of experimental $(W \rightarrow W$ and $R \rightarrow W$ ) groups exceeds that of the control group on early List 2 trials should increase as number of List 1 trials increases, and the point of crossover with the control group should occur later. (3) Because of the greater frequency buildup for List $1 \mathrm{R}$ items than for List $1 \mathrm{~W}$ items, the effect of varying List 1 trials should be more pronounced for $\mathrm{R} \rightarrow \mathrm{W}$ transfer conditions than for $W \rightarrow W$ conditions. METHOD

Eighty-seven paid Ss were recruited from the summer session at the University of Iowa. There were $12 \mathrm{Ss}$ assigned randomly to each of six experimental groups and 15 Ss assigned to the control group.

All groups had the same 16 List 1 VD pairs. The control group had entirely new List 2 items. The three groups in the $\mathrm{W} \rightarrow \mathrm{W}$ transfer paradigm had the same new $R$ items on List 2 as did the control group, with the $W$ items from List 1 becoming the W items on List 2. The three groups in the $R \rightarrow W$ transfer paradigm had the same List $2 \mathrm{R}$ items as did the control group and the $W \rightarrow W$ groups; the $R$ items from List 1 became the $W$ items on List 2. All groups received 10 trials on List 2. The control group received 4 trials on List 1 . The experimental groups received 2,4 , or 8 trials on List 1. The six experimental groups are labeled $\mathrm{W} \rightarrow \mathrm{W}(2), \mathrm{W} \rightarrow \mathrm{W}(4)$, $\mathrm{W} \rightarrow \mathrm{W}(8), \quad \mathrm{R} \rightarrow \mathrm{W}(2), \quad \mathrm{R} \rightarrow \mathrm{W}(4)$, $\mathrm{R} \rightarrow \mathrm{W}(8)$, depending on the transfer paradigm and number of List 1 trials.

All lists consisted of 16 pairs of three- and four-letter low-frequency words selected from the Thorndike \& Lorge (1944) word count. Interlist and intralist similarity were minimized, and the pairings of $R$ and $W$ items 

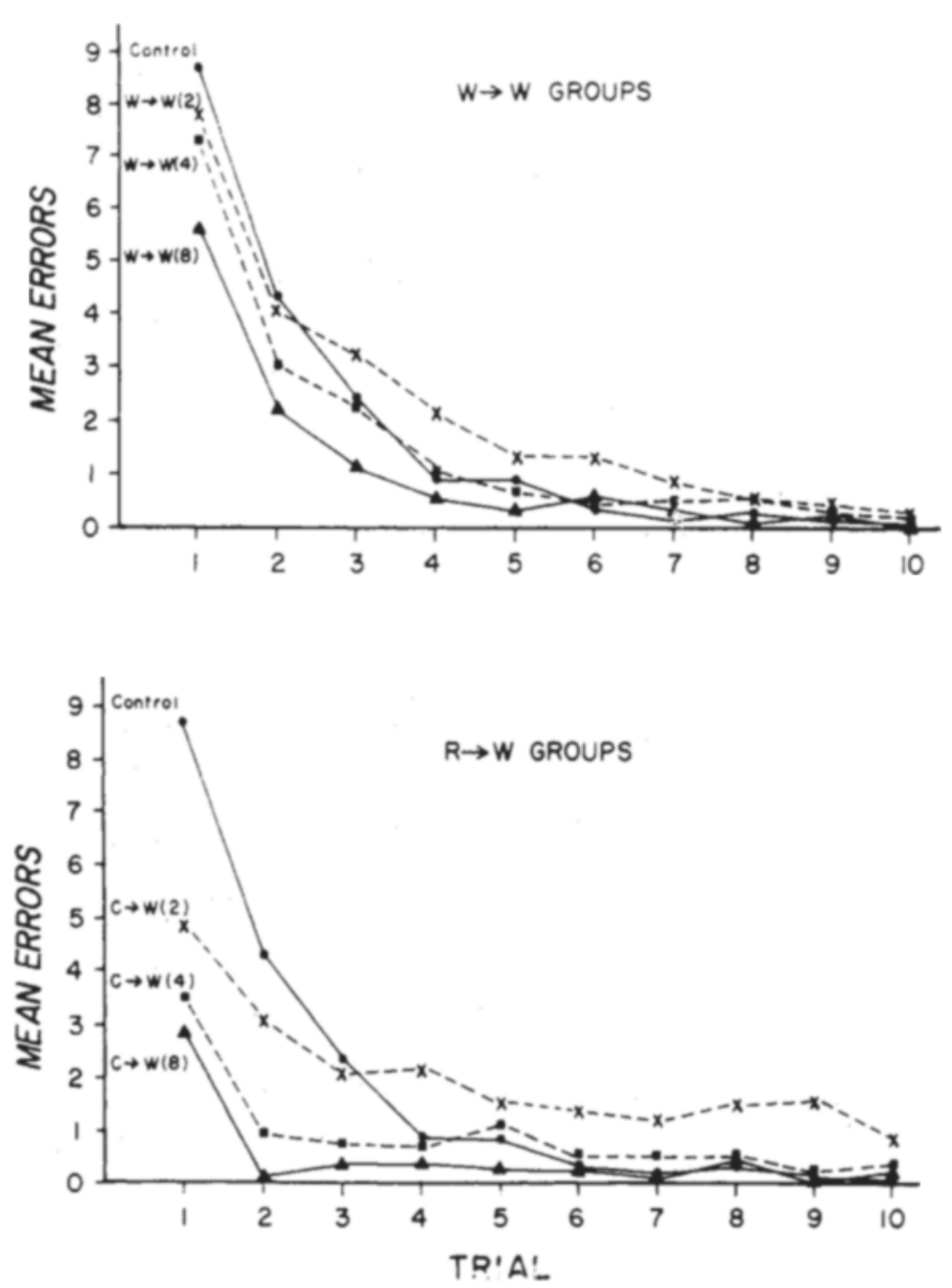

Fig. 1. Mean learning curves on List 2.

were random. Four random orders of List 1 items and five random orders of List 2 items were constructed. Using a memory drum, List 1 pairs were presented for $2 \mathrm{sec}$, with a subsequent interval of $2 \mathrm{sec}$, during which $S$ made his choice aloud and then $E$ read the correct response aloud. Following completion of List $1, \mathrm{~S}$ left the room for $1 \mathrm{~min}$ while $E$ changed the memory drum tape. Upon reentering the room, $\mathrm{S}$ was told that he would be given a new list of pairs from which to choose, but unlike the Underwood et al (1964) study, Ss were not informed of any possible relationship between List 1 and List 2 items. List 2 trials were presented with a $1.5-\mathrm{sec}$ study period and a $2 \cdot \mathrm{sec}$ response interval.

Because List 1 items were equated across groups, List $2 \mathrm{~W}$ items differed between groups. In order to insure that the lists were comparable in difficulty, supplementary data were collected in a single-list VD task using List 2 pairs. New groups of eight Ss each learned each of the three
Groups with the same number of List 1 trials were compared with each greater for the control group other on mean number of List 1 errors. In no case did group differences approach statistical significance at the .05 level.

The mean learning curve for each group on List 2 is given in Fig. 1. Groups in the $W \rightarrow W$ transfer paradigm are shown in the upper panel; groups in the $\mathrm{R}-\mathrm{W}$ paradigm are shown in the lower panel. For comparison purposes, the control group is included in each panel. It can be seen that group differences tend to be consistent with the predictions of frequency theory. On initial trials within each paradigm, the experimental groups made fewer errors than did the control group, with the errors decreasing as number of List 1 trials increased and the differences being greater for $R-W$ groups than for $W-W$ groups. On later trials, performance of the control group catches up or surpasses that of the experimental groups, with the intersection point between the curve for the control group and each experimental group tending to occur later as the number of List 1 trials increases.

Separate statistical analyses were conducted for $W-W$ groups plus the control group and for $\mathrm{R} \rightarrow \mathrm{W}$ groups plus the control group. Analyses of variance revealed highly significant group differences and Group by Trial interactions. To assess the reliability of initial group differences, linear trend tests were conducted using mean errors on the first trial of List 2. The linear trend component was significant across Groups Control, $\mathrm{W} \rightarrow \mathrm{W}(2)$, $\mathrm{W} \rightarrow \mathrm{W}(4)$, and $\mathrm{W} \rightarrow \mathrm{W}(8)$, and the linear trend component was significant across Groups Control, $R \rightarrow W(2)$, $\mathrm{R} \rightarrow \mathrm{W}(4)$, and $\mathrm{R} \rightarrow \mathrm{W}(8)$, $\mathrm{F}(1,47)=8.02$ and 18.30 , respectively, $p<.01$ in each case.

Comparisons between each experimental group and the control group before and after the intersection point of the mean learning curves are

Table 1

Differences Between Mean Errors for Experimental and Control Groups on List 2

\begin{tabular}{|c|c|c|c|c|c|}
\hline Groups Compared & Trials & \begin{tabular}{l}
\multicolumn{1}{c}{ Mean } \\
Difference \\
Per Trial*
\end{tabular} & t Value & df & Significance \\
\hline$W \rightarrow W(2)$ vs Control & $1 \cdot 2$ & 0.66 & 1.08 & 25 & n.s. \\
\hline$W \rightarrow W(2)$ vs Control & $3-10$ & -0.63 & 2.38 & 25 & $\mathrm{p}<.05$ \\
\hline$W \rightarrow W(4)$ vs Control & $1-3$ & 0.91 & 1.26 & 25 & n.s. \\
\hline$W \rightarrow W(4)$ vs Control & $4-10$ & -0.14 & 0.67 & 25 & n.s. \\
\hline$W \rightarrow W(8)$ vs Control & $1-5$ & 1.51 & 2.72 & 25 & $\mathrm{p}<.01$ \\
\hline$W \rightarrow W(8)$ vs Control & $6-10$ & -0.04 & 0.38 & 25 & n.s. \\
\hline $\mathrm{R} \rightarrow \mathrm{W}(2)$ is Control & $1-3$ & 1.82 & 2.16 & 25 & $\mathrm{p}<.05$ \\
\hline$R-W(2)$ vs Control & $4-10$ & -1.08 & 2.51 & 25 & $\mathrm{p}<.01$ \\
\hline$R \rightarrow W(4)$ vs Control & $1-4$ & 2.79 & 4.42 & 25 & $\mathrm{p}<.01$ \\
\hline$R \rightarrow W(4)$ vs Control & $5-10$ & -0.27 & 1.29 & 25 & n.s. \\
\hline$R \rightarrow W(8)$ vs Control & $1-7$ & 1.93 & 5.64 & 25 & $\mathrm{p}<.01$ \\
\hline$R-W(8)$ vs Control & $8-10$ & -0.03 & 0.38 & 25 & n.s. \\
\hline
\end{tabular}

* Positile differences indicate that the mean number of errors per trial per $S$ uas 
summarized in Table 1. It can be seen that differences with the control group are larger and more reliable for $R \rightarrow W$ groups than for $W \rightarrow W$ groups. However, the trends are similar within each transfer paradigm. As the number of List 1 trials increases, differences favoring the experimental groups on precrossover trials tend to increase and differences favoring the control group on postcrossover trials tend to decrease. For experimental groups with eight List 1 trials, the mean learning curve is nearly coincident with that of the control group on trials following the initial point of intersection and appears to represent a ceiling effect.

\section{DISCUSSION}

Transfer performance in the present study was generally consistent with the predictions of frequency theory, even though instructions to $S$ did not reveal the relationship between List 1 and List 2 items. This not only supports the basic concepts of the theory, but argues for the utility of varying List $I$ trials as a direct means of manipulating subjective frequency. A comparison of transfer paradigms $W-W$ and $R \rightarrow W$ shows that frequency effects are more pronounced in the latter paradigm, even though the former is more commonly employed. It is suggested that the $R-W$ VD transfer paradigm warrants further usage.

The use of the $W \rightarrow W$ and $R-W$ transfer paradigms in the same experiment can yield additional information concerning the constructs of frequency theory. Ekstrand et al (1966) discuss frequency components which, when combined, yield a frequency ratio of at least 2:1 in favor of the $R$ item over the $W$ item within a given VD pair. These authors, however, do not specify how to get a quantitative estimate of that ratio. In the present case, such an estimate is possible by comparing the relative frequency of carryover from the end of List 1 to the start of List 2 within each paradigm. Comparing the upper and lower panels of Fig. 1, it can be seen that mean errors on the first trial of List 2 was approximately the same for Groups $W-W(8)$ and $R-W(2)$. Thus eight trials with an incorrect item had about the same effect as two trials with a correct item, suggesting a frequency ratio of approximately $4: 1$ in favor of an $R$ item over a $W$ item. This value possibly changes over trials and is probably not generalizable beyond the procedures of the present study, but an expansion of this method of estimating the ratio may prove useful ir quantifying the theory.

Finally, the reason why performance does not deteriorate on late List 2 trials for groups with eight List 1 trials warrants discussion. This can be accounted for by an extension of frequency theory recently suggested by Hintzman \& Block (1971). They assume that Ss can discriminate recent from remote frequency through the use of multiple memory traces underlying frequency representation. In the present case, this would account for why the performance of Groups $W \rightarrow W(8)$ and $R \rightarrow W(8)$ did not deteriorate on late List 2 trials. Hintzman and Block suggest that Ss separate memory traces on the basis of the time lag associated with each. The present results suggest that increasing the number of List 1 trials facilitates the discrimination of List 1 frequency from List 2 frequency.

\section{REFERENCES}

EKSTRAND, B. R. WALLACE, W. P.. \& UNDERWOOD, B. J. A frequency theory of verbal-discrimination learning. Psychological Review, 1966, 73, 566-578.

HINTZMAN, D. L.. \& BLOCK, R. A. Repetition and memory: Evidence for a multiple-trace hypothesis. Joumal of Experimental Psychology. 1971. 88. 297-306.

RASKIN. D. C.. BOICE. C., RUBEL, E. W. \& CLARK, D. Transfer tests of the frequency theory of verbal-discrimination learning. Joumal of Experimental Psychology. 1968, 76, 521-529.

THORNDIKE, E L., \& LORGE, I. The teacher's word book of 30.000 words. New York: Bureau of Publications. Teachers College. Columbia University. 1944 .

UNDERWOOD, B. J., JESSE, F.. \& EKSTRAND. B. R. Knowledge of rights and wrongs in verbal-discrimination learning. Journal of Verbal Leaming \& Verbal Behavior, 1964, 3, 183-186. 